Document downloaded from:

http://hdl.handle.net/10251/63844

This paper must be cited as:

Torregrosa Jaime, B.; Bjurling, F.; Corberán Salvador, JM.; Di Sciullo, F.; Payá Herrero, J. (2015). Transient thermal model of a vehicle's cabin validated under variable ambient conditions. Applied Thermal Engineering. 75:45-53. doi:10.1016/j.applthermaleng.2014.05.074.

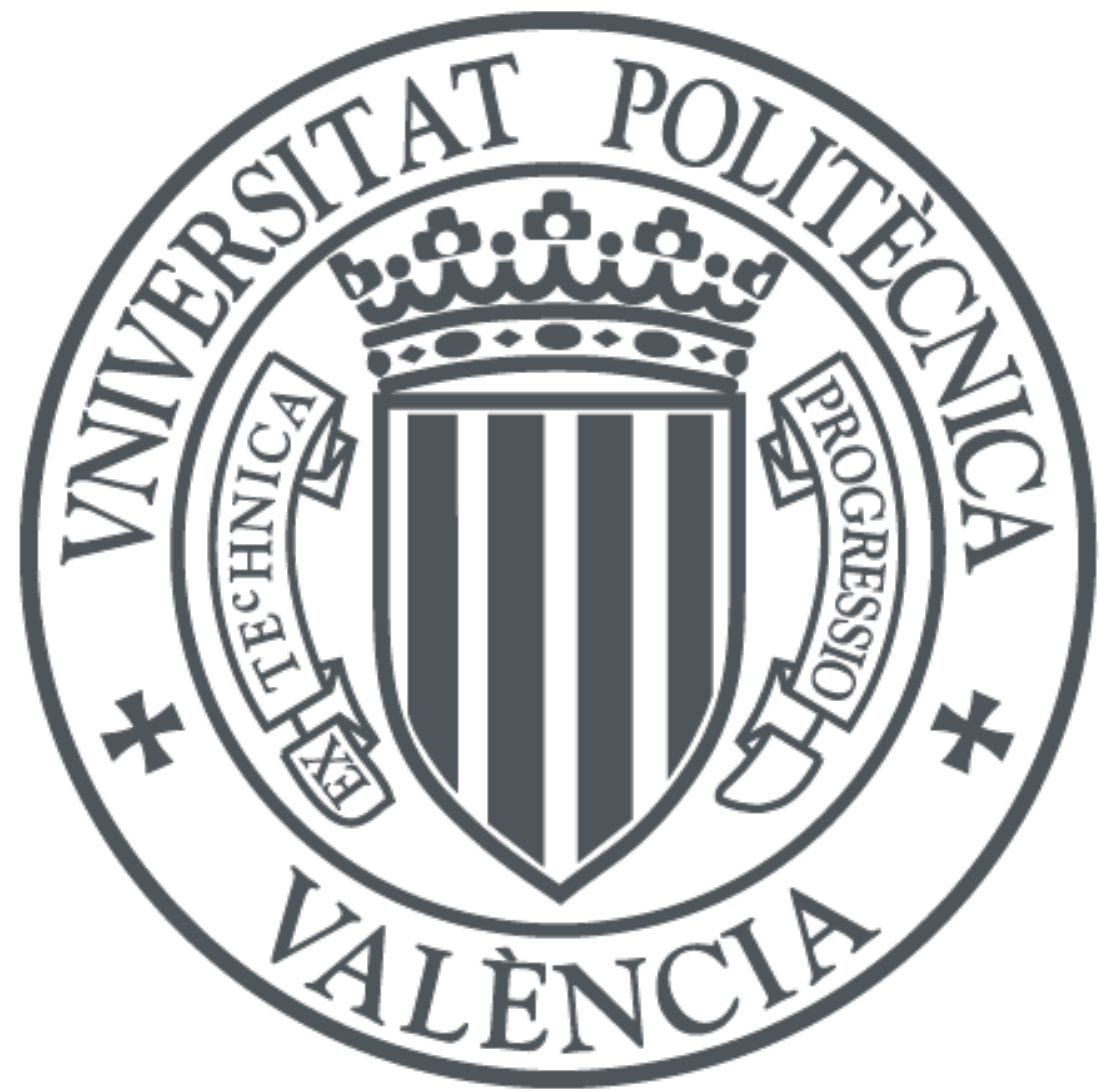

The final publication is available at

http://dx.doi.org/10.1016/j.applthermaleng.2014.05.074

Copyright Elsevier

Additional Information 


\title{
Transient thermal model of a vehicle's cabin validated under
}

\section{variable ambient conditions}

\author{
Bárbara Torregrosa-Jaime ${ }^{a}$, Filip Bjurling ${ }^{a}$, José M. Corberán ${ }^{a}$, Fausto Di Sciullo ${ }^{b}$, Jorge \\ Payáa,* \\ ${ }^{a}$ Instituto de Ingeniería Energética (IIE), Universitat Politècnica de València \\ Camino de Vera s/n, Edificio 8E cubo F planta 5, 46022 Valencia, Spain \\ ${ }^{b}$ Centro Ricerche Fiat (CRF), Strada Torino 50, 10043 Orbassano (TO), Italy
}

\begin{abstract}
This paper presents a lumped-parameter thermal model of the passengers' compartment of a vehicle. The model is completely dynamic and has been thoroughly validated under variable ambient conditions including solar radiation. The proposed model reproduces accurately the warm-up and cool-down of the cabin and can help analyse capacity reduction actions for air-conditioning systems.

In this study, the thermal loads have been calculated by means of the model. For the tested minibus in real outdoor conditions, air renewal represents from $7 \%$ up to $53 \%$ of the thermal load, while the solar radiation accounts for $18 \%$ to $31 \%$. According to the results, a decrease of 0.2 in the glazing transmissivity can lead to a $3.3 \%$ reduction of the installed cooling capacity.
\end{abstract}

Keywords: Automotive, Modeling, Simulation, Thermal load, Air conditioning

*Corresponding author. Tel: +34 963879910; Fax: +34 963877272;

E-mail address: jorpaher@iie.upv.es (J. Payá) 


\begin{tabular}{|c|c|c|c|}
\hline \multicolumn{4}{|c|}{ NOMENCLATURE } \\
\hline \multirow[b]{2}{*}{$A$} & \multirow[b]{2}{*}{ Surface $\left[\mathrm{m}^{2}\right]$} & \multicolumn{2}{|l|}{ Subcripts } \\
\hline & & $i$ & Internal air \\
\hline C & Heat capacity [J K-1] & $A C$ & Air conditioning \\
\hline$c_{p}$ & Specific heat capacity [ $\left.\mathrm{J} \mathrm{K}^{-1} \mathrm{~kg}^{-1}\right]$ & $\operatorname{aux}$ & Auxiliaries \\
\hline$F$ & View factor $[-]$ & $B$ & Back \\
\hline$g$ & 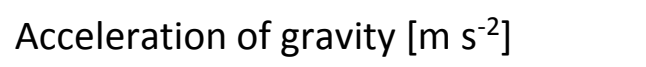 & $b$ & Beam \\
\hline$\Delta h_{v a p}$ & Enthalpy of vaporization $\left[\mathrm{J} \mathrm{kg}^{-1}\right]$ & $d$ & Diffuse \\
\hline I & $\begin{array}{l}\text { Global solar irradiance on horizontal } \\
\text { surface }\left[\mathrm{W} \mathrm{m}^{-2}\right]\end{array}$ & $e$ & External air \\
\hline$I^{\prime}$ & $\begin{array}{l}\text { Global solar irradiance on tilted } \\
\text { surface }\left[\mathrm{W} \mathrm{m}^{-2}\right]\end{array}$ & $F$ & Front \\
\hline$m$ & Mass $[\mathrm{kg}]$ & $g$ & Glazing \\
\hline$\dot{m}$ & Mass flow rate $\left[\mathrm{kg} \mathrm{s}^{-1}\right]$ & $H$ & Horizontal \\
\hline$\dot{Q}$ & Heat load [W] & $L$ & Left \\
\hline$T$ & Temperature $[\mathrm{K}]$ & $l$ & Latent \\
\hline$t$ & Time $[s]$ & $m$ & Interior mass \\
\hline$U$ & $\begin{array}{l}\text { Overall heat transfer coefficient } \\
{\left[\mathrm{W} \mathrm{K}^{-1} \mathrm{~m}^{-2}\right]}\end{array}$ & occ & Occupants \\
\hline$\dot{V}$ & Volumetric flow rate $\left[\mathrm{m}^{3} \mathrm{~s}^{-1}\right]$ & out & Outlet \\
\hline \multirow[t]{2}{*}{$W$} & Humidity ratio $\left[\mathrm{kg}_{\text {water vapor }} \mathrm{kg}_{\text {dry air }}{ }^{-1}\right]$ & $R$ & Right \\
\hline & & $r$ & Reflected \\
\hline \multicolumn{2}{|c|}{ Greek symbols } & ret & Return \\
\hline$\alpha$ & Absorptivity [-] & $s$ & Sensible \\
\hline$\beta$ & Recirculation ratio [-] & sky & Sky \\
\hline$\delta$ & Distribution ratio [-] & sol & Solar \\
\hline$\epsilon$ & Emissivity [-] & sup & Supply \\
\hline$\rho$ & Density $\left[\mathrm{kg} \mathrm{m}^{-3}\right]$ & ven & Ventilation \\
\hline$\sigma$ & $\begin{array}{l}\text { Stefan-Boltzmann constant } \\
{\left[\mathrm{W} \mathrm{m}^{-2} \mathrm{~K}^{-4}\right]}\end{array}$ & $w$ & Cabin walls \\
\hline \multirow[t]{2}{*}{$\tau$} & Transmissivity [-] & 1 & Thermal zone 1 \\
\hline & & 2 & Thermal zone 2 \\
\hline
\end{tabular}

\section{Introduction}

The air-conditioning $(\mathrm{AC})$ of a vehicle has to ensure a thermal comfort for the occupants and perform safety tasks such as the window defogging. However, its 
utilization has a significant impact on the energy balance of vehicles. From NREL estimations [1], the AC can reduce fuel economy by $20 \%$ in mid-sized conventional vehicles and autonomy by $16 \%$ in fully electric vehicles (FEVs). Additionally, in the case of FEVs the AC must also heat up the vehicle, which in winter can reduce autonomy by $8 \%$ to $24 \%$ depending on the chosen technology [2]. In view of these figures, the optimisation of the AC system by means of simulations can help to improve substantially the performance of vehicles.

This work focuses on the simulation of the thermal behaviour of the passengers' compartment of a vehicle, namely the cabin. Among published literature on cabin thermal models, 3D CFD models or lumped-parameter models have been developed [3]. 3D models are employed to analyse in detail thermal comfort aspects, while lumped-parameter models are more appropriate for the integration of the cabin model with the AC system or a control system. In fact, since lumped-parameter models assume that the air properties are uniformly distributed, they offer a better compromise between accuracy and computational cost.

Several lumped-parameter thermal models of cabins have been reported up to now. For instance, Gado [4] developed a cabin model which was part of a facility to test the AC system independently of the vehicle. Other authors such as Li and Sun [5] have modelled a cabin coupled with an AC unit. Cabin models are often useful to evaluate the effect of different conditions or technologies on the cooling load or on the internal temperatures. Maidment and Missenden [6] studied the influence of several factors on the temperature of subway carriages. Liu et al. [7] calculated the cooling load in a train compartment. Levinson et al. [8] analyzed the benefits of solar reflective car shells.

The main purpose of the thermal models of cabins is to predict the air temperature inside the cabin. In addition, some models predict the relative humidity [4-6], which also affects comfort and window fogging.

For design purposes, it is often convenient to evaluate the internal temperatures when exposed to severe conditions, such as for high ambient temperatures, intensive radiation or with a significant passenger load. Some studies include the calculation of the solar radiation in detail in order to reproduce dynamic conditions. Sanaye et al. [9] and Khayyam et al. [10] built cabin models including this feature and focused on the control system of the AC. Huang [11], Conceição et al. [12] and Mezrhab and Bouzidi [13] developed cabin thermal models with a high level of detail. However, only Mezrhab and Bouzidi [13] include radiative heat transfer between surfaces. Few models consider other significant loads such as heat from engine and exhaust [10] or from auxiliaries [5].

Heat storage in the external and internal structures also has a significant influence on the air temperature within the time which is necessary for a cool-down or a warm-up 
of a vehicle [14]. In order to take this effect into account, several authors [11-13] consider the composition of the cabin walls in detail. This approach requires full information about the cabin characteristics, which is generally not given in manufacturer data of the vehicle. Using an overall heat transfer coefficient can avoid this issue, but the models which employ them usually neglect heat storage either in the cabin walls $[4-6,8,9]$ or in the objects installed inside the cabin, which are referred to as the interior mass $[5-8,10]$.

Furthermore, there is generally not a thorough validation with experimental data. An exception can be found at Conceição et al. [12], who provide dynamic tests under real outdoor conditions for a railway car parked during several hours and running at a fixed speed during an hour. Nevertheless, to the authors' knowledge simulation results have not been validated yet with measurements under different ambient conditions or along several days.

In this work, a new lumped-parameter thermal model of the cabin is presented. Unlike previous models, it includes thermal inertia of the cabin walls and the interior mass using the overall heat transfer coefficient approach. Another significant novelty is that it includes two thermal zones inside the vehicle. The model has been validated thoroughly with experimental tests under different ambient conditions.

Although the thermal behaviour of the cabin depends on specific characteristics of the simulated vehicle, a general methodology to obtain the parameters is explained. In this study, the model has been applied to an electric minibus, specifically the ALTRA Daily which is being used in the European Project ICE [15].

\section{Model description}

The transient thermal model of the cabin which has been developed enables the calculation of the mean temperature and relative humidity of the air inside the cabin. These parameters are essential for the design and control of mobile air-conditioning systems.

A diagram of the cabin model is shown in Fig. 1. The air inside the cabin is confined by the cabin walls and the interior mass. The cabin is divided into two thermal zones: the driver's region (zone 1) and the passengers' region (zone 2). This approach is interesting in mobile air conditioning since the occupation of the passengers' region can be very variable. 
In each thermal zone, the air conditions are affected by several energy and mass flows: convection with surrounding surfaces $\left(\dot{Q}_{i-w}\right.$ and $\left.\dot{Q}_{i-m}\right)$, air supply from the AC system $\left(\dot{m}_{A C}\right)$, air circulation between zones $\left(\dot{m}_{1-2}\right)$, load due to the occupants $\left(\dot{Q}_{o c c}\right)$ and load due to electrical auxiliaries $\left(\dot{Q}_{\text {aux }}\right)$ such as the blowers. The ventilation air flow $\left(\dot{m}_{v e n}\right)$ does not enter the cabin directly but affects the air mass balance. The excess air $\left(\dot{m}_{\text {out }}\right)$, if any, leaves the cabin through the vents located at the rear of the vehicle. In addition, a distribution ratio $(\delta)$ has been introduced to account for the supply air from the HVAC module in the dashboard (zone 1 ) which goes directly to the passengers' region (zone 2).

At the same time, the temperature of the cabin walls is influenced by heat transfer with the ambient $\left(\dot{Q}_{e-w}\right)$ and with the air inside the cabin $\left(\dot{Q}_{i-w}\right)$; by incident solar radiation $\left(\dot{Q}_{s o l, w}\right)$ and also by heat transfer by long wave radiation between the vehicle body and the sky $\left(\dot{Q}_{w-s k y}\right)$ and with the internal mass of the vehicle $\left(\dot{Q}_{m-w}\right)$.

The temperature of the interior mass also changes dynamically due to the convective heat transfer with the cabin air $\left(\dot{Q}_{i-m}\right)$, to the solar radiation passing through the glazing $\left(\dot{Q}_{s o l, m}\right)$ and to radiative heat transfer with the cabin walls $\left(\dot{Q}_{m-w}\right)$.

In electric vehicles the motor and the batteries operate at relatively low temperatures [16] so heat transfer with their compartments can be ignored.

The model calculates the temperature and moisture of the cabin air, as well as the temperature of the cabin walls and the interior mass, by means of energy and mass balances in each thermal zone, taking into account the terms listed before. As explained in section 1 , the model is based in the lumped capacitance method and assumes that the temperature of each element and the relative humidity of the air are spatially uniform.

Eqs. (1-3) represent the energy balances of the cabin air, the cabin walls and the interior mass, respectively, for zone 1 . The equations for zone 2 are analogue. Conduction between zones is neglected due to the narrow contact surface. The air density $\left(\rho_{i}\right)$ and specific heat capacity $\left(c_{p, i}\right)$ are considered to be constant.

$$
\begin{aligned}
C_{i 1} \cdot \frac{d T_{i 1}}{d t}= & \dot{Q}_{s u p 1}+\dot{Q}_{a u x 1}+\dot{Q}_{o c c 1, s}-\dot{Q}_{i 1-w 1}-\dot{Q}_{i 1-m 1} \\
& -\dot{V}_{1-2} \cdot \rho_{i} \cdot c_{p, i} \cdot\left(T_{1}-T_{2}\right)
\end{aligned}
$$


Eqs. (4-5) are the moisture mass balances in the cabin air for zone 1 and zone 2 respectively. The recirculation ratio $\beta=\dot{m}_{r e t} / \dot{m}_{A C}$ expresses the amount of air supplied by the AC in each zone which is recirculated from the cabin. This term has been introduced to represent conveniently the air mass balance illustrated in Fig. 1.

$$
\begin{aligned}
V_{i 1} \cdot \rho_{i} \cdot \frac{d W_{i 1}}{d t} & =\dot{V}_{A C 1} \cdot \rho_{i} \cdot\left(\delta \cdot W_{A C 1}-\beta_{1} \cdot W_{i 1}-\left(\delta-\beta_{1}\right) \cdot W^{*}\right)+\frac{Q_{o c c 1, l}}{\Delta h_{v a p}} \\
& -\dot{V}_{1-2} \cdot \rho_{i} \cdot\left(W_{i 1}-W_{i 2}\right) \\
V_{i 2} \cdot \rho_{i} \cdot \frac{d W_{i 2}}{d t} & =\dot{V}_{A C 1} \cdot \rho_{i} \cdot\left((1-\delta) \cdot W_{A C 1}+\left(\delta-\beta_{1}\right) \cdot W^{*}-\left(1-\beta_{1}\right) \cdot W_{i 2}\right) \\
& +\dot{V}_{A C 2} \cdot \rho_{i} \cdot\left(W_{A C 2}-W_{i 2}\right)+\frac{Q_{o c c 2, l}}{\Delta h_{v a p}}+\dot{V}_{1-2} \cdot \rho_{i} \cdot\left(W_{i 1}-W_{i 2}\right)
\end{aligned}
$$

Where $W^{*}$ is equal to $W_{i 1}$ if $\delta>\beta_{1}$ or $W_{i 2}$ if $\delta<\beta_{1}$.

In Eq. (4), the first term of the right hand side represents the moisture mass which enters and leaves the control volume of zone 1 due to the air supply from airconditioning and air renewal. The second term accounts for the moisture mass due to the latent heat emitted by the occupants in zone 1 . Finally, the third term is the moisture mass that enters and leaves the zone 1 due to air circulation between zones (see section 2.5).

Similarly, in Eq. (5) the first term of the right hand side accounts for the moisture mass from the air supply in zone 1 that enters the zone 2, as well as for the air renewal from zone 1 as illustrated in Fig. 1 . The second term is the moisture mass associated to the air supply from air-conditioning in zone 2 . The third and fourth terms are analogue to Eq. (4) and represent the moisture mass due to the latent heat from the occupants and to the air circulation between zones respectively.

\subsection{Load due to the air supply}

The sensible thermal load due to the air supply from air-conditioning and air renewal $\left(\dot{Q}_{\text {sup }}\right)$ is included in the equations considering the air mass balance in each thermal zone illustrated in Fig. 1 and the previous definition of the recirculation ratio $(\beta)$.

$$
\begin{aligned}
& \dot{Q}_{\text {sup } 1}=\dot{V}_{A C 1} \cdot \rho_{i} \cdot c_{p, i} \cdot\left(\delta \cdot T_{A C 1}-\beta_{1} \cdot T_{i 1}-\left(\delta-\beta_{1}\right) \cdot T^{*}\right) \\
& \dot{Q}_{\text {sup } 2}=\dot{V}_{A C 1} \cdot \rho_{i} \cdot c_{p, i} \cdot\left((1-\delta) \cdot T_{A C 1}+\left(\delta-\beta_{1}\right) \cdot T^{*}-\left(1-\beta_{1}\right) \cdot T_{i 2}\right) \\
& +\dot{V}_{A C 2} \cdot \rho_{i} \cdot c_{p, i} \cdot\left(T_{A C 2}-T_{i 2}\right)
\end{aligned}
$$

Where $T^{*}$ is equal to $T_{i 1}$ if $\delta>\beta_{1}$ or $T_{i 2}$ if $\delta<\beta_{1}$. 


\subsection{Load from the electrical auxiliaries}

The main electrical auxiliaries that bring heat inside the cabin are the blowers of the AC system. Their associated heat load $\left(\dot{Q}_{a u x}\right)$ is introduced directly in the model from manufacturer data. For instance, a typical minibus has one AC blower installed in the dashboard which produces $311 \mathrm{~m}^{3} / \mathrm{h}$ of air flow and consumes $290 \mathrm{~W}$ at its maximum speed. Two additional blowers are installed at the rear of the vehicle, which can deliver up to $500 \mathrm{~m}^{3} / \mathrm{h}$ of air with a consumption of $247 \mathrm{~W}$ each.

\subsection{Load from occupants}

The load from occupants is divided into sensible $\left(\dot{Q}_{o c c, s}\right)$ and latent heat $\left(\dot{Q}_{o c c, l}\right)$. In each thermal zone, the latter gains are calculated by multiplying the number of occupants by the heat load generated per person. According to ASHRAE [17], a seated person emits $70 \mathrm{~W}$ of sensible heat and $35 \mathrm{~W}$ of latent heat.

\subsection{Heat transfer between air and surfaces}

In order to account for the convective heat transfer between air and surfaces combined with the conductive processes inside the solid bodies, a lumped capacitance has been fitted for each air-solid interaction. Eq. (8) corresponds to the heat transfer between the cabin air and the cabin walls $\left(\dot{Q}_{i-w}\right)$. A similar expression applies for the heat transfer between the ambient air and the cabin walls $\left(\dot{Q}_{e-w}\right)$ or between the cabin air and the interior mass $\left(\dot{Q}_{i-m}\right)$.

$\dot{Q}_{i-w}=U_{i-w} \cdot A_{w} \cdot\left(T_{i}-T_{w}\right)$

\subsection{Air circulation between zones}

Since there is no physical barrier between the two thermal zones, the air can circulate freely between them. The air flow due to the stack effect between zones communicated by a single aperture of height $H$ and surface $A_{1-2}$ can be expressed as in Eq. (9) [17], where zone 1 is warmer than zone 2.

$\dot{V}_{1-2}=\left(0.40+0.0045 \cdot\left|T_{1}-T_{2}\right|\right) \cdot A_{1-2} \cdot \sqrt{g \cdot H \cdot\left(T_{1}-T_{2}\right) / T_{1}}$

\subsection{Solar radiation load}


Solar radiation acts as an energy gain on the cabin walls and it depends on the incident irradiance on each side of the vehicle $\left(I^{\prime}\right.$ side $)$ as well as on the mean absorptivity of the cabin walls $\left(\alpha_{w}\right)$, which includes both metallic and glazed surfaces (Eq. 10).

$\dot{Q}_{\text {sol, } w}=\alpha_{w} \cdot \sum I_{\text {side }}^{\prime} A_{\text {side }, w} \quad($ side $=R, L, F, B$ and $H)$

In addition, the incident radiation penetrates through the glazing and consequently, the energy gain in the internal masses includes the incident solar irradiance multiplied by the transmissivity of the glasses $(\tau)$ and by the absorptivity of the interior mass $\left(\alpha_{m}\right)$ (Eq. 11). For simplicity, and given that the seats and the dashboard are black, the interior mass is considered a black body.

$\dot{Q}_{\text {sol, } m}=\alpha_{m} \cdot \tau \cdot \sum I_{\text {side }}^{\prime} A_{\text {side, },} \quad($ side $=R, L, F$ and $B)$

The transmissivity of the glazing decreases if the angle of incidence of the sun rays increases. Nevertheless, this effect was analysed initially with the model and it is hardly noticeable given that it only affects in the sunrise and sunset, when the incident radiation is small. In order to keep the computational cost lower, a constant transmissivity has been used.

In a first attempt solar radiation was included in the model as a simple energy gain proportional to the measured incident irradiance on horizontal surface. However, it was impossible to reach a good validation and thus a key point in the model was to include the effect of the variable sun position throughout the day.

The incident radiation on each side of the vehicle was consequently introduced by means of the calculation scheme followed by many simulation programs such as TRNSYS [18]. Firstly, the components of radiation on a horizontal surface are calculated from experimental data $\left(I\right.$ and $\left.T_{e}\right)$. Then, the radiation components on a tilted surface are computed: beam irradiance $\left(I_{b}^{\prime}\right)$, reflected irradiance $\left(I_{r}^{\prime}\right)$ assuming ground is an isotropic reflector and diffuse irradiance $\left(I_{d}^{\prime}\right)$. Finally, the global irradiance on a tilted surface is given by $I^{\prime}=I^{\prime}{ }_{b}+I^{\prime}{ }_{r}+I^{\prime}{ }_{d}$.

\subsection{Radiative heat transfer}

Eq. (12) expresses the radiative heat transfer between the cabin walls and the interior mass $\left(\dot{Q}_{m-w}\right)$. A two surface enclosure approach has been applied in each thermal zone [19] and all the internal surfaces inside the vehicle are assumed to behave as blackbodies. The glazing is considered to be opaque to long wave radiation [13].

$\dot{Q}_{m-w}=\sigma A_{m} F_{m-w}\left(T_{m}^{4}-T_{w}^{4}\right)$ 
The radiative heat transfer between cabin walls and the sky $\left(\dot{Q}_{w-s k y}\right)$ is expressed in Eq. (13) assuming that the cabin walls behave as a small convex object in a large cavity [19].

$\dot{Q}_{w-s k y}=\sigma \epsilon_{w} A_{H, w}\left(T_{w}^{4}-T_{s k y}^{4}\right)$

\section{Results and discussion}

The cabin model has been validated for the ALTRA Daily electric minibus by means of two experimental tests under different ambient conditions. The first one is a warm-up and cool-down inside a garage, while the second one is under ambient conditions for several days, including solar radiation.

In order to validate the model, the minibus dimensions were taken from manufacturer data and they are listed in Table 1 . The radiation heat transfer parameters, which are summarized in Table 2, were obtained from literature and are also coherent with existing models $[7,10]$.

On the other hand, some of the parameters of the model cannot be deduced from manufacturer data or literature due to the complex geometry of the vehicle. These are the overall heat transfer coefficients $(U)$ and the thermal capacities of the cabin walls $\left(C_{w}\right)$ and the interior mass $\left(C_{m}\right)$.

The overall heat transfer coefficients are mainly convective. Upper and lower limits have been established based on literature [19] and the exact values for this application have been obtained by calculating the heat transfer coefficients which minimize the mean square deviation between the experimental tests and the simulations. The results are shown in Table 3.

The heat transfer coefficients of the internal surfaces $\left(U_{i-w}\right.$ and $\left.U_{i-m}\right)$ in the garage test are larger during the warm-up since there is forced convection induced by the fans, which are off during the cool-down. Since the internal surfaces of the vehicle reach similar temperatures, $U_{i-w}$ and $U_{i-m}$ were given the same value in each case. However, in the tests with radiation the temperature gradients inside the vehicle are higher, which explains why the convective heat transfer is higher than during the cooldown inside the garage. Moreover, in the test with solar radiation the interior mass heats up considerably and acts as a heated plane facing upwards [19]. Therefore it is logical to obtain higher convective coefficients than in the cabin walls. Additionally, the heat transfer coefficient with the ambient air $\left(U_{e-w}\right)$ is logically higher in the tests with radiation given that these were carried out in open-air conditions whereas the other tests were carried out inside a garage, consequently with less movement of air. In any 
case, the values obtained are coherent with those found in literature on cabin models $[11,22]$. However, the correlations presented in heat transfer bibliography [19] lead to lower values of the heat transfer coefficient, ranging from 2 to $4 \mathrm{~W} \mathrm{~m}^{-2} \mathrm{~K}^{-1}$. This fact was also observed by [12] and can be explained by the vehicle geometry. While the empirical correlations in [19] refer to simple isolated surfaces, the vehicle geometry is rather complex.

Regarding the heat capacity, $C_{w}$ and $C_{m}$ were estimated considering the mass of the vehicle $(3700 \mathrm{~kg})$ and the average specific heat capacity of its main components, such as steel, glass and plastic $\left(C=m c_{p}\right)$. The values obtained were tuned in order to minimize the mean square deviation between the measurements and the simulations. On the other hand, $C_{i}$ was calculated directly from the cabin volume and the air properties. The results are shown in Table 4.

The cabin model was programmed in Matlab-Simulink using the S-Function tool, which enables to write directly the differential equations. The parameters used to obtain the simulation results presented in this work are listed in Tables 1-4. The initial conditions for the simulations correspond to the temperature measurements at the beginning of each test.

\subsection{Experimental test 1: warm-up and cool-down in a garage}

The first validation test was carried out with the minibus parked inside a garage with the purpose of validating the model regardless of solar radiation. Two fan-heaters of $2000 \mathrm{~W}$ each were placed along the corridor of the vehicle. They were turned on at the beginning of the test in order to heat up the cabin. After 160 minutes, the fan-heaters were turned off and the cabin cooled down due to natural convection. The temperature of the air inside the cabin was measured with T-Type thermocouples with an uncertainty of $\pm 0.5 \mathrm{~K}$. The thermocouples were placed at four locations at head level, as shown in Fig. 2. Temperature measurements were registered every $30 \mathrm{~s}$.

In order to simulate this test, the thermal load due to the fan heaters was considered as a sensible heat gain. Additionally, during the warm-up part the stack effect was enhanced to take into account the air circulation imposed by the activation of the fan heaters. A value of $4000 \mathrm{~W} \mathrm{~K}^{-1}$ equilibrates the temperatures obtained in both zones.

Fig. 3 shows the experimental and simulation results of test 1 on the cabin air temperature. The results are only shown for zone 1 because they are almost identical for zone 2. In fact, the maximum temperature difference between the two zones is 0.7 $\mathrm{K}$. This is due to the lack of a physical barrier between both zones, as well as to the air mixing produced by forced convection. 
Despite the initial part of the warm-up, which can be influenced by the inertia of the thermocouples, the model reproduces very well the experimental results.

\subsection{Experimental test 2: minibus parked under the sun}

A second experimental test was carried out in Torino (Italy) during several days of July when the minibus was parked under the sun facing west. The temperatures inside the vehicle were measured as shown in Fig. 4 by means of T-Type thermocouples with an uncertainty of $\pm 0.5 \mathrm{~K}$. In total, twelve thermocouples were placed: two for the air temperature plus two for the interior mass in zone 1 and four for the air temperature at head level plus four in the seats in zone 2.

Additionally, a pyranometer Lp pyra 02 delta ohm (uncertainty $1.5 \%$ at $\mathrm{T}_{\mathrm{a}}=23^{\circ} \mathrm{C}$ and $50 \% \mathrm{RH}$ ) was placed on the roof of the minibus to measure the global solar irradiance on horizontal surface. The ambient temperature was also measured by means of a TType thermocouple (uncertainty of $\pm 0.5 \mathrm{~K}$ ) protected against the solar radiation.

Fig. 5 shows the ambient temperature and the global solar irradiance on horizontal surface measured during the experimental campaign, which started at 0:00 h. These data, as well as the mean sky temperature in Torino [23], were introduced as inputs in the cabin model. Figs. 6 and 7 show the comparison between measured and simulated results.

In Fig. 5, the global solar irradiance on horizontal surface $(I)$ changes abruptly when it is cloudy and takes then a value around $0.2 \mathrm{~kW} \mathrm{~m}^{-2}\left(I \approx I_{d}\right)$. If Fig. 5 is compared to Figs. 6-7, it is observed that solar irradiance affects directly to the temperatures inside the vehicle, causing peaks. In contrast, the variation of the external temperature makes the internal temperatures change smoothly.

Fig. 6 shows the results for the mean air temperature in zone 1 . As in test 1 , the values obtained in zone 2 are very similar due to the lack of a physical barrier between zones. The maximum difference between zones is $1.5 \mathrm{~K}$. As can be observed, the model predicts very accurately the experimental results, even the peaks caused by solar irradiance. On the contrary, the heat transfer coefficients predicted by literature provide less accurate results. These coefficients have a low value, therefore heat transfer between the cabin air and the cabin walls decreases. The heat from solar irradiation is blocked inside the cabin causing the air temperature to increase.

Fig. 7 illustrates the mean temperature of the interior mass in both zones. The temperatures reached in zone 2 are lower due to the tinted glazing in the passengers' region (lower transmissivity). The minibus was facing west, which explains why in the evening the solar radiation affects mainly the zone 1 . The model reproduces accurately 
the experimental results, although it slightly overpredicts the temperature in zone 2 for high solar irradiance. This can be due to the fact that a single overall heat transfer coefficient was fitted for both zones. In fact, the temperatures predicted in zone 2 are very close to the cabin air temperature shown in Fig. 6 . In addition, the temperature was measured only in the seats, while the model considers a lumped heat capacity for all the objects installed inside the cabin.

The cabin energy balance during the third day measured is pictured in Fig. 8. Positive values represent heat entering the cabin, while negative values indicate heat losses. The solar radiation absorbed by the cabin walls is a major heat gain, but convection with the ambient air and radiation to sky counteract its effect. The result of this balance depends on the absorptivity of the cabin walls, which in the case of the tested white minibus is rather low. Therefore, in test 2 the air inside the cabin is heated up mainly due to natural convection with the interior mass, which receives the solar radiation through the glazing. The orientation of the vehicle and the properties of the glasses affect significantly the value of this gain, as can be seen when comparing its value in zone $1\left(\dot{Q}_{s o l, m 1}\right)$ and in zone $2\left(\dot{Q}_{s o l, m 2}\right)$.

The cooling capacity required to maintain the cabin at the comfort temperature can be obtained directly from the cabin model if the thermal loads due to occupation, auxiliaries and ventilation are considered. For instance, Fig. 9 shows the cooling capacity required to maintain the Daily cabin at $25^{\circ} \mathrm{C}$ under the hardest conditions measured during test 2 (after $63 \mathrm{~h}: T_{e}=29.1^{\circ} \mathrm{C}, I=913.62 \mathrm{~W} \cdot \mathrm{m}^{-2}$ ). The minibus is assumed to be fully occupied (18 people) and the AC flow is fully renewed.

The breakdown of the required cooling capacity in Fig. 9 shows that all the loads considered are significant. Among them, convection with the interior mass has the largest global contribution. In addition, as shown in Fig. 8, this effect influences significantly the hot soak temperature. Therefore, reducing the value of the transmissivity of the glazing by increasing its reflectivity can contribute significantly to reduce the installed capacity.

If the heat transfer coefficients estimated from literature are employed, the steadystate load turns out to be $10 \%$ lower. Since the predicted heat transfer coefficients are lower than the adjusted ones, the heat load due to convection with the interior mass and with the cabin walls decreases.

Fig. 10 shows the required cooling capacity obtained with different values of the transmissivity of the passengers' glazing $\left(\tau_{2}\right)$. In this case, reducing $\tau_{2}$ by 0.2 reduces required cooling capacity in steady state by $3.3 \%$. Moreover, it lowers by $1.2 \mathrm{~K}$ the hot soak temperature, which could potentially decrease AC compressor power by $4 \%$ [8].

Obviously, the results shown in Figs. 9-10 depend on the design conditions. Fig. 11 shows the cooling capacity required under different ambient conditions, assuming full 
air renewal and full air recirculation. As in former calculations, the comfort temperature is $25^{\circ} \mathrm{C}$, the cabin is fully occupied and the minibus is facing west at $3 \mathrm{p} . \mathrm{m}$. in Torino.

As can be observed in Fig.11, at the steady state the cooling load has a linear dependence with the ambient temperature. This is consistent with Eq. (1) if all the other conditions, such as solar irradiance or air renewal flow, remain constant. Measured [24] and simulated [5] results from other authors support the linear trend.

An increase in the ambient temperature not only affects the convective heat transfer, but also increases dramatically the load due to air renewal. Similar results were observed in [5]. The load due to air renewal can represent up to a $53 \%$ of the cooling load required to keep the minibus at $25^{\circ} \mathrm{C}$. If air renewal load is not considered, the cooling load required increases $136.9 \mathrm{~W}$ per every $1 \mathrm{~K}$ increase of the ambient temperature.

Solar irradiance also plays a significant role. In fact, a difference of $2804 \mathrm{~W}$ in the required cooling load has been calculated between the conditions measured ( $I=923 \mathrm{~W}$ $\left.\mathrm{m}^{-2}\right)$ and a cloudy day $\left(I \approx I_{d} \approx 200 \mathrm{~W} \mathrm{~m}^{-2}\right)$.

AC systems in thermally powered vehicles are usually tested in full recirculation mode under severe weather conditions, such as $40^{\circ} \mathrm{C}$ at $50 \% \mathrm{RH}$ and I=900 W m $\mathrm{W}^{-2}$. In addition, buses are usually tested considering full occupancy. The test begins at hot soak conditions and is divided in two parts. Firstly, the vehicle is running and then it is stopped with the engine idling. In this case, the cooling capacity required to maintain $25^{\circ} \mathrm{C}$ inside the minibus cabin after the cool-down under typical testing conditions is $7.54 \mathrm{~kW}$. This value is similar to the $7.85 \mathrm{~kW}$ obtained under real outdoor conditions considering full air renewal (Fig. 9).

\section{Conclusion}

A transient thermal model of the cabin of a minibus has been developed and thoroughly validated with experimental data. The model can be useful for analysing installed capacity reduction actions, as well as for sizing AC systems or studying their interaction with the cabin.

The analysis of the thermal loads performed on the tested minibus has shown that solar radiation influences significantly the thermal behaviour of the cabin, since it hits directly on the interior mass which in turn heats up the air. Hence, an accurate 
calculation of the incident radiation and the separation in zones with different glazing characteristics have been key points to reproduce accurately the dynamics of the warm-up and cool-down of the cabin in real outdoor conditions.

Finally, the cooling capacity required at steady state was calculated considering different design conditions. In the case of the tested minibus, air renewal can take from $7 \%$ to $53 \%$ of the required cooling capacity depending on ambient temperature, while solar radiation passing through the glazing represents between $18 \%$ and $31 \%$ of the cooling demand. Therefore, air renewal control and tinted glazing can result in a significant reduction of the installed cooling capacity in vehicles.

As future work, the presented cabin model will be integrated with an AC system model whose operation will be optimized to reduce the overall energy consumption.

\section{Acknowledgements}

This work has been supported by the European Commission under the $7^{\text {th }}$ European Community framework program as part of the ICE project "MagnetoCaloric Refrigeration for Efficient Electric Air-Conditioning", Grant Agreement no. 265434. B. Torregrosa-Jaime acknowledges the Spanish Science and Innovation Ministry (Ministerio de Ciencia e Innovación) for receiving the Research Fellowship FPU ref. AP2010-2160.

\section{References}

[1] R.B. Farrington, J.P. Rugh, Impact of Vehicle Air-Conditioning on Fuel Economy, Tailpipe Emissions and Electric Vehicle Range, NREL Report CP-540-28960, Golden, Colorado, USA, 2000.

[2] D. Clodic, E. Zgheib, S. Mortada, Impacts of Heating and Cooling on Electrified Vehicles, 4th European Workshop Mobile Air Conditioning and Vehicle Thermal Systems 2011, Torino, 2011.

[3] A. Alahmer, A. Mayyas, A.A. Mayyas, M.A. Omar, D. Shan, Vehicular thermal comfort models; a comprehensive review, Appl. Therm. Eng. 31 (2011) 995-1002.

[4] A. Gado, Development of a dynamic test facility for environmental control systems, PhD Thesis, University of Maryland, College Park, Maryland, USA, 2006.

[5] W. Li, J. Sun, Numerical simulation and analysis of transport air conditioning system integrated with passenger compartment, Appl. Therm. Eng. 50 (2013) 37-45. 
[6] G.G. Maidment, J.F. Missenden, Evaluation of an underground railway carriage operating with a sustainable groundwater cooling system, Int. J. Refrig. 25 (2002) 569574.

[7] W. Liu, Q. Deng, W. Huang, R. Liu, Variation in cooling load of a moving airconditioned train compartment under the effects of ambient conditions and body thermal storage, Appl. Therm. Eng. 31 (2011) 1150-1162.

[8] R. Levinson, H. Pan, G. Ban-Weiss, P. Rosado, R. Paolini, H. Akbari, Potential benefits of solar reflective car shells: Cooler cabins, fuel savings and emission reductions, Appl. Energy 88 (2011) 4343-4357.

[9] S. Sanaye, M. Dehghandokht, A. Fartaj, Temperature control of a cabin in an automobile using thermal modeling and fuzzy controller, Appl. Energy 97 (2012) 860868.

[10] H. Khayyam, A.Z. Kouzani, E.J. Hu, S. Nahavandi, Coordinated energy management of vehicle air conditioning system, Appl. Therm. Eng. 31 (2011) 750-764.

[11] D.C. Huang, A dynamic computer simulation model for automobile passenger compartment climate control and evaluation, PhD Thesis, Michigan Technological University, Michigan, USA, 1998.

[12] E.Z.E. Conceição, M.C.G. Silva, J.C.S. André, D.X. Viegas, A Computational Model to Simulate the Thermal Behaviour of the Passengers Compartment of Vehicles, SAE Technical Paper 1999-01-0778 (1999).

[13] A. Mezrhab, M. Bouzidi, Computation of thermal comfort inside a passenger car compartment, Appl. Therm. Eng. 26 (2006) 1697-1704.

[14] Ö Arici, S. Yang, D. Huang, E. Öker, Computer Model for Automobile Climate Control System Simulation and Application, International Journal of Applied Thermodynamics 2 (1999) 59-68.

[15] ICE Project FP7, www.ice-mac-ev.eu, 2014, last accessed 03/03/2014.

[16] B. Torregrosa-Jaime, J. Payá, J. Corberan, Design of Efficient Air-Conditioning Systems for Electric Vehicles, SAE International Journal of Alternative Powertrains 2 (2013) 291-303. 
[17] ASHRAE, 2009 ASHRAE Handbook. Fundamentals. SI Edition, ASHRAE, Atlanta, USA, 2009.

[18] Solar Energy Laboratory, Type 16: Solar Radiation Processor, in: TRNSYS 16 Mathematical Reference, University of Wisconsin-Madison, Madison, USA, 2007, pp. 286-295.

[19] F.P. Incropera, Fundamentals of Heat and Mass Transfer, sixth, Wiley, Hoboken, New Jersey, USA, 2007.

[20] M. Modest, Radiative Properties of Real Surfaces, in: Radiative Heat Transfer, third ed., Academic Press, USA, 2013, pp. 61-128.

[21] P. Berdahl, S.E. Bretz, Preliminary survey of the solar reflectance of cool roofing materials, Energy Build. 25 (1997) 149-158.

[22] J. Meyer, HMC sonata: thermal energy efficient vehicle, SAE Automotive Alternate Refrigerant Systems Symposium, Scottsdale, Arizona, 2002.

[23] US Department of Energy, EnergyPlus, 2013.

[24] J.P. Powell, A. González-Gil, R. Palacin, Experimental assessment of the energy consumption of urban rail vehicles during stabling hours: influence of ambient temperature, Appl. Therm. Eng. (2014), doi: 10.1016/j.applthermaleng.2014.02.057. 